Recaived f ${ }^{\mathrm{PNL}-\mathrm{SA}-\mathrm{-18761}}$

JAN 281

AN INTEGRATED MISSION APPROACH TO

THE SPACE EXPLORATION INITIATIVE

WILL ENSURE SUCCESS

E. P. Coomes

J. E. Dagle

J. A. Bamberger

K. E. Noffsinger

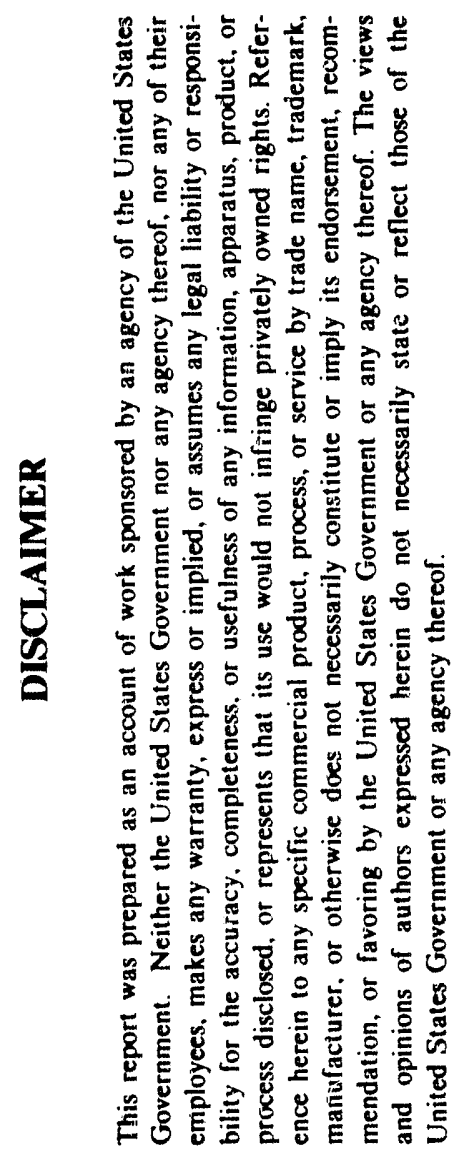

October 1990

Presented at

8 th Symposium on Space

Nuclear Power Systems

Albuquerque, New Mexico

January 6-10, 1991

Work Supported by

the U.S. Department of Energy

under Contract DE-ACO6-76RLO 1830

Pacific Norihwest Laboratory

Richland, Washington 99352 
LOG \#_150_

Session \#_14_

\section{AN INTEGRATED MISSION APPROACH TO THE SPACE EXPLORATION INITIATIVE WILL ENSURE SUCCESS}

Edmund P. Coomes, Jeffery E. Dagle,

Judith A. Bamberger, and Kent E. Noffsinger

Pacific Northwest Laboratory

P.O. Box 999 M/S K5-21

Richland, WA 99352

(509) 375-2549

CAMERA READY MANUSCRIPT

Prepared for:

Eight Symposium on

Space Nuclear Power Systems

Albuquerque, New Mexico

6-10 January 1991

Initial submission: 24 July 1990

Address all correspondence to: Mr. Edmund P. Coomes

Work supported by

the U.S. Department of Energy

under Contract DE-AC06-76RLO 1830 


\title{
AN INTEGRATED MISSION APPROACH TO THE SPACE EXPLORATION INITIATIVE WILL ENSURE SUCCESS
}

\author{
Edmund P. Coomes, Jeffery E. Dagle, \\ Judith A. Bamberger, and Kent E. Noffsinger \\ Pacific Northwest Laboratory \\ P.O. Box $999 \mathrm{M} / \mathrm{S}$ K5-21 \\ Richland, WA 99352 \\ (509) $375-2549$
}

\begin{abstract}
$\underline{\text { Abstract }}$
The direction of the American space program, as defined by President Bush and the National Commission on Space, is to expand human presence into the solar system. Landing an American on Mars by the 50th anniversary of the Apollo 11 lunar landing is the goal. This challenge has produced a level of excitement among young Americans not seen for nearly three decades. The exploration and settlement of the space frontier will occupy the creative thoughts and energies of generations of Americans well into the next century. The return of Americans to the moon and beyond must be viewed as a national effort with strong public support if it is to become a reality. Key to making this an actuality is the mission approach selected. Developing a permanent presence in space requires a continual stepping outward from Earth in a logical progressive manner. If we seriously plan to go and to stay, then not only must we plan what we are to do and how we are to do it, we must address the logistic support infrastructure that will allow us to stay there once we arrive. A fully integrated approach to mission planning is needed if the Space Exploration Initiative (SEI) is to be successful. Only in this way can a permanent human presence in space be sustained. An integrated infrastructure approach would reduce the number of new systems and technologies requiring development. The resultant horizontal commonality of systems and hardware would reduce the direct economic impact of SEI while an early return on investment through technology spin-offs would be an economic benefit by greatly enhancing our international technical competitiveness. If the exploration, development, and colonization of space is to be affordable and acceptable, careful consideration must be given to such things as "return on investment" and "commercial product potential" of the technologies developed. This integrated approach will win the Congressional support needed to secure the financial backing necessary to assure that the President's long-range vision of human expansion into the solar system becomes a reality.
\end{abstract}

\section{INTRODUCTION}

Energy is the one requirement common to all space missions and, therefore, the cornerstone on which mankind's development and colonization of space will be built. Given an abundant supply of energy, mankind's ingenuity and inventiveness will overcome the obstacles that must be faced. The lack of adequate energy to support the desired mission objectives has always handicapped mission planners forcing them into mission objective concessions. Power beaming is an integrated approach to providing energy for a broad range of mission applications and is unconstrained by the final end use of the energy delivered. Power beaming is a space power utility approach separating production from use. It allows each mission planner the same access to power, yet preserves the individuality of mission requirements and objectives. Power beaming will reduce the concessions mission planners must make while increasing mission objectives possible.

\section{MISSIOIJ APPLICATIONS}

Mission planning is always an exercise in compromise, trading off mission goals and objectives that can be achieved with a given payload against the amount of on-board power that can be packed into the finite platform volume available. Power beaming provides two major mission benefits: increased power for less volume of the platform used and, of equal if not greater importance, a highly transportable and very versatile method of supplying power. 
The Air Force has recognized the value of electric propulsion and has made it the baseline propulsion technology for future satellite transfer from low Earth orbit (LEO) to geosynchronous Earth orbit (GEO). The Air Force is also carefully examining the possibility of using electric propulsion to provide satellite mobility as a means of enhancing satellite survivability. Increased power availability and/or the reduction in photovoltaic panel area are advantages provided by power beaming that would greatly enhance military space mission capabilities.

The National Aeronautics and Space Administration (NASA) is examining the viability of putting a permanently manned base on the moon and in Mars. These bases will have a variety of power requirements to maintain the base and sustain the space explorers. Surface activities away from the base, such as transportation, exploration, resource utilization, will also require energy. Energy for manned transport vehicles and unmanned rovers will be needed to support these remote surface activities. The logistic support for these bas $ı s$ will require the use of highly efficient cargo transport vehicles, such as an electric propulsion (EP) driven space transport, for resupply of materials and equipment. A multimegawatt-class electric cargo transport with a long-life nuclear electric power source, when coupled with an easily transported bea:n-power transmission system, takes on new importance and value by doubling as the surface energy source after its cargo load is delivered (Bamberger 1990).

\section{Near-Earth Mission Applications}

The first step in expanding human presence into the solar system involves near-Earth operations and activities because they are major drivers for the space exploration missions that follow. NearEarth mission applications are a mix of both military and civilian systems operating from LEO to GEO, equatorial to polar orbits. LEO satellites include remote sensing, intelligence gathering, and research satellites, while GEO spacecraft consist primarily of communications satellites (Wilson 1990). In between are navigation satellites. These sate!lites typically use solar panels and lightweight batteries to provide the required power. In the tear term, communications satellite operators are not likely to embrace power-beaming technology. However, the increased power demand for direct broadcast television and the anticipated market this will have may entice these users into adopting power beaming for future satellites.

As the energy requirements increase, power system mass and volume become significant factors. For example, meeting Space Station Freedom's (SSF) energy requirements is a difficult problem. The initial design required an average power of $75 \mathrm{kWe}$ (for housekeeping, attached payload requirements, and experiment modules). This requirement was met using eight large solar arrays covering a total of over $2200 \mathrm{~m}^{2}$. Station designers are now considering reducing this to $37.5 \mathrm{~kW}$, but still over $1100 \mathrm{~m}^{2}$ of solar panel area will be needed. Utilizing power beaming, a 7.5-m diameter laser beam receiver could provide the station with upwards of $120 \mathrm{kWe}$ (Coomes, Bamberger, and McCauley 1990). The beam-power satellite supplying this would consist of a growth SP-100 reactor producing $650 \mathrm{kWe}$, well within the capability of SP-100 technology, and a $325-\mathrm{kW}$ laser transmitter. Three beam-power satellites, spaced $120^{\circ}$ in a $20,000-\mathrm{km}$ orbit, could provide SSF with continuous power allowing the on-board batteries to remain fully charged and be reserved for emergency power only. Pointing the laser beam receiver at the sun would provide another 5 to $10 \mathrm{kWe}$ of emergency power.

Dynamic conversion systems with 50-ft diameter solar concentrators are being developed to meet SSF growth power requirements. Each unit would produce $25 \mathrm{kWe}$ of usable power with another $25 \mathrm{kWe}$ available for recharging batteries. With continuous power beaming, the usable output power of each system would be doubled to $50 \mathrm{kWe}$ because battery discharge would not be necessary. The sun becomes a backup option with usable output cut back to $25 \mathrm{kWe}$ and battery cycling again required to provide power during umbra. 
The Industrial Space Facility (ISF) is planned to be a man-tended Earth-orbiting platform where research and manufacturing operations will be conducted. The ISF will use solar arrays to provide up to $10.8 \mathrm{kWe}$ to its customers and will require a panel area of approximately $250 \mathrm{~m}^{2}$. Also power beaming could provided the ISF with upwards of $120 \mathrm{kWe}$. With the ISF $120^{\circ}$ out of phase with the station, it too could be provided continuous power from the same beam-power satellites. Polar platforms, being studied as part of NASA's Mission to Planet Earth, could be supplied 20 to $40 \mathrm{kWe}$ as multiple users of the same beam-power satellites.

Independent of the above missions, the development and deployment of a beam-powered electric Earth orbital transfer vehicle (EOTV) operating between LEO and GEO (Dagle 1991) would justify power beaming. An operational beam-powered EOTV would require three beam-power satellites to provide continuous power. The dry weight of such an EOTV would be about $690 \mathrm{~kg}$, excluding tankage, with a maximum payload to GEO of $6000 \mathrm{~kg}$ and a gross deployed weight in LEO of about $7220 \mathrm{~kg}$ giving an $80 \%$ payload fraction delivering to or returning payloads from GEO (Dagle and Coomes 1989). Returning payloads to LEO is a capability our space transportation system does not yet possess. A comparable chemical propulsion system, using advanced engine technology, would require a gross weight of over $22 \mathrm{MT}$ to deploy the same payload and is a one-way system. While the tiip time for the chemical system is hours, a beampowered EOTV would take 100 days to deliver its payload but cost per kilogram delivered would be only half that of a chemical system. In addition, the low thrust of electric propulsion would allow the satellite to be transported fully deployed. Satellites could be operationally checked out in LEO prior to deployment and repaired or retumed to Earth if necessary, saving millions of dollars worth of hardware.

The implementation of power beaming in Earth orbit is an innovative approach to space power generation and distribution (SPGD) and would develop a technology base with a very broad range of applicability (Coomes, Johnson, and Widrig 1990). Because it involves near-Earth operations and activities (major technology drivers for the space exploration missions that follow), SPGD is a near-term application of power beaming and serves as the first step in an energy-based mission planning approach to expanding human presence into the solar system. The near-Earth deployment of power beaming would accomplish two primary goals: advanced power and propulsion systems would be developed and space qualified; a return on investment would occur because power beaming, as a space power utility, would be a highly profitable commercial venture. Figure 1 is an artist's rendition of an Earth-orbiting SPGD utility.

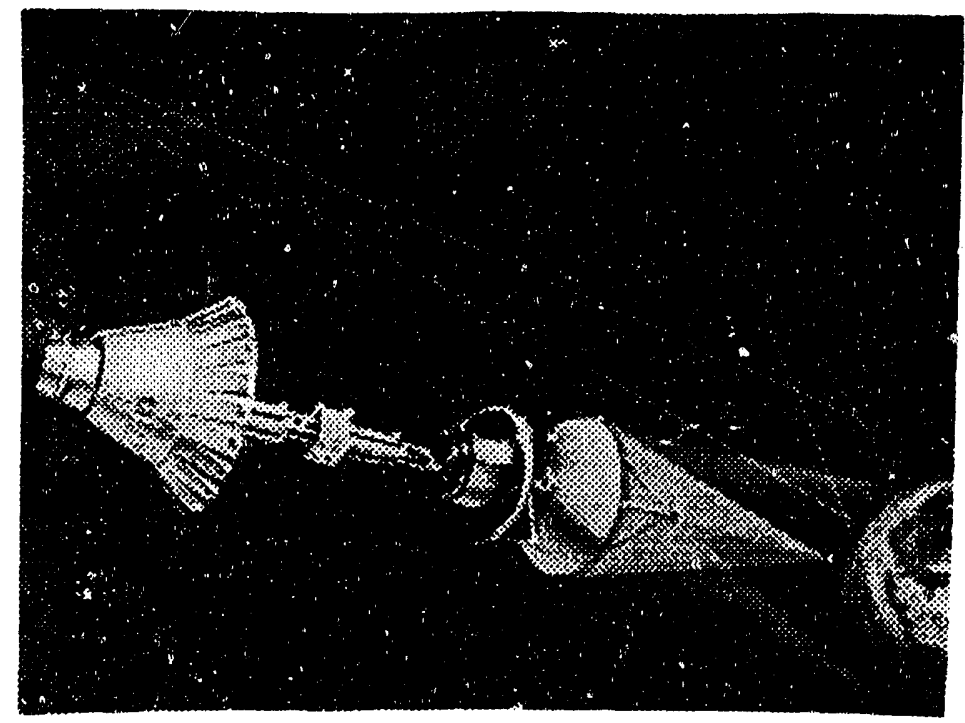

FIGURE 1. A Space Power Utility Using Power Beaming 


\section{Lunar Mission Applications}

Consider the situation where power beaming is fully implemented in support of near-Earth operations and mankind is ready to establish a manned lunar base. By now, the first generation of beam-power satellites in Earth orbit are reaching the end of their operational life. Systematically, each old bearn-power satellite is being replaced with a second-generation beam-power satellite. These second-generation power systems will have output capabilities upwards of 10-MWe. The development of power beaming for near-Earth applications has made available the power and propulsion technologies needed to provide logistics support for a permanently manned lunar base.

A cargo vehicle will be needed to deliver the initial materials and equipment for the lunar base. Later a ileet of cargo transport vehicles will be needed to provide continued logistical support to the lunar base and to provide growth. A nuclear electric cargo transporter would be an excellent choice and straightforward to construct, based on the beam-powered EOTV and power satellite technologies developed for near-Earth applications. With a nuclear electric lunar cargo vehicle, the prime power source for a lunar beam-power transmission system would already be available. The lunar transporter would deliver its cargo to the proper lunar parking orbit and then move out and take up position at the L1 libration point 35,000 miles above the lunar surface. From this point, a 10-MW nuclear electric power system could provide upwards of $5 \mathrm{MW}$ of electrical power for use on the lunar surface.

The application of power beaming to lunar missions would greatly enhance current planned activities while enabling new mission options not previously considered possible because of power limitations. Figure 2 is a conceptual drawing of a beam-powered lunar base

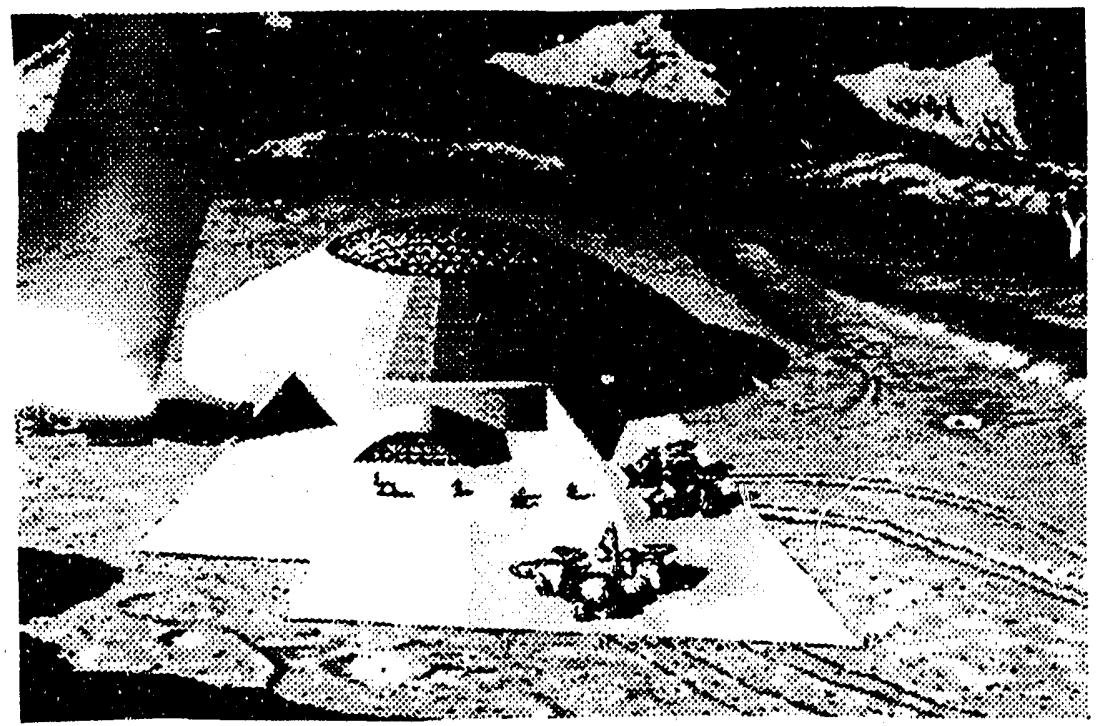

FIGURE 2. A Beam-rowered Lunar Base

\section{Mars Mission Applications}

By now the lunar base is a small colony building toward economic self-sufficiency. Lunar resources are being processed to provide materials, feed stock, and equipment for Earth orbital activities. Lunar oxygen is being utilized in place of terrestrial oxygen for fuel in the space transportation and environmental systems. Expended beam-power satellites are being transferred to the lunar colony for refurbishment and returned to service. Mankind is again ready to expand outward. Establishing an outpost on Mars is a logical progression and becomes a natural extrapolation of the infrastructures established for near-Earth and lunar activities. The beam-power 
infrastructure transported to Mars would be a seasoned technology with a significant operating history. Upon arrival, power beaming could be implemented directly, eliminating the need to land large surface power systems, making surface power available almost immediately.

The split-sprint Mars mission scenario would be very attractive. Staging for the Mars mission could occur in both lunar and Earth orbit. An unmanned nuclear electric cargo vehicle, staged in lunar orbit, could be sent to Mars carrying all the necessary supplies and equipment necessary to $\mathrm{e}^{\prime}$ ablish the outpost. The manned mission, staged in Earth orbit, would follow later using either a chemical or nuclear thermal propulsion system. The use of a separate nuclear electric-propelled cargo vehicle offers several unique mission options (Coomes and Bamberger 1990) not possible with a chemically-powered cargo vehicle:

- Being sent in advance, it could carry return or reserve fuel for the manned return flight.

- A backup return vehicle would be available should the primary manned space craft become disabled. The crew could reconfigure the two spacecraft (already in orbit around Mars) and use the propulsion system of the cargo vehicle to propel them home.

- Taking advantage of the fuel savings offered by electric propulsion and with no need for the life support, habitat, or additional shielding systems required on a manned vehicle, the cargo transport vehicle could carry enough supplies in a single flight to support several manned flights to Mars.

- Coupling the nuclear electric power system to a beam-power transmission system, electric power can be supplied from geosynchronous Mars orbit (GMO) to the surface to support a broader range of activities.

- Automated systems deployed fiom the cargo vehicle or left operating when the crew returns to Earth could convert raw materials on the Mars surface into usable form, which would then be available to the manned flights that follow.

Upon arrival at Mars, the transport vehicle would deliver its cargo to the desired parking orbit and move outward, taking a position in GMO above the desired landing sight. From there it would beam power to the Mars surface to support crew activities after their arrival, as shown in Figure 3.

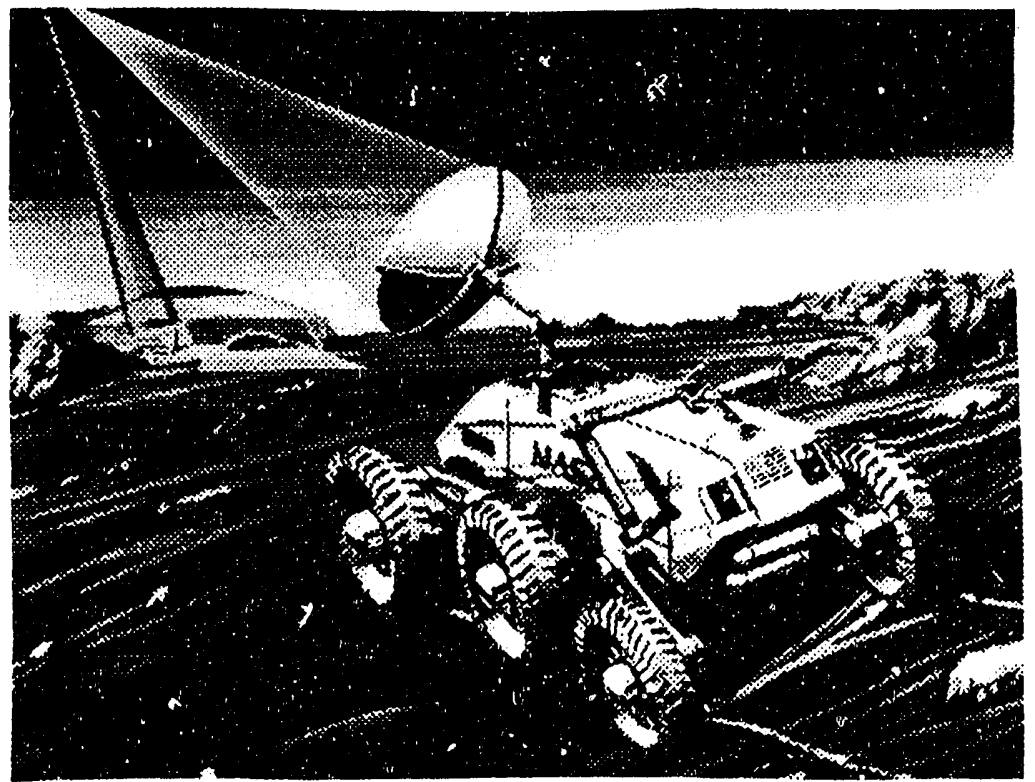

FIGURE 3. N.ars Base and Surface Exploration with Power Beaming 
With megawatt levels of electric power available on the Mars surface, mission activities could be expanded allowing accelerated development and growth of a Mars colony.

\section{CONCLUSIONS}

A fully integrated approach to mission planning is needed if the Space Exploration Initiative is to be successful. An integrated infrastructure approach would reduce the number of new systems and technologies requiring development. The resultant horizontal commonality of systems and hardware would reduce the direct economic impact of SEI and provide an economic benefit by greatly enhancing our international technical competitiveness through technology spin-offs and through the resulting early return on investment. Consideration of return on investment, rather than mission cost, and integrated multimission planning has never before been attempted in space exploration planning. Integrated planning and close interagency cooperation must occur if the SEI is to achieve its goal of expanding the human presence into the solar system. A mission planning approach based on providing energy by power beaming gives each mission planner the needed power, yet preserves the individuality of mission requirements and objectives and reduces the concessions mission planners must make.

\section{Acknowledgments}

This work was performed at the Pacific Northwest Labcratory, and supported by the U.S. Department of Energy under Contract Number DE-AC06-76RLO 1830. The Pacific Northwest Laboratory is operated for the U.S. Department of Energy by Battelle Memorial Institute.

\section{References}

Bamberger, J.A. (1990) "A New Method for Power Generation and Distribution in Outer Space," in Proceedings: Seventh Symposium on Space Nuclear Power Systems, M. S. El-Genk and M. D. Hoover, eds., Vol. 1, pp 387-392, Institute for Space Nuclear Power Studies Albuquerque, NM.

Coomes, E.P. and J.A. Bamberger (1990) "Applications and Space Mission Enhancements Made Possible with a Nuclear-Driven Beam-Power System," in Proceedings: Seventh Symposium on Space Nuclear Power Systems, M.S. El-Genk and M.D. Hoover, eds., Vol. 1, pp 16-20, Institute for Space Nuclear Power Studies Albuquerque, NM.

Coomes, E.P., J.A. Bamberger, and L.A. McCauley (1990) An A ssessment of the Impact of Free Space Electromagnetic Energy Transmission of Strategic Defense Initiative Systems and Architectures, PNL-6932, Pacific Northwest Laboratory, Richland, WA.

Coomes, E.P., B.M. Johnson, and R.D. Widrig (1990) Space Power Generation and Distribution (SPGD) Program Basis Document, PNL-7162, Pacific Northwest Laboratory, Richland, WA.

Dagle, J.E. (1991) "Power Considerations For Electric Propulsion Earth Orbital Transporters Utilizing Power Beaming," in Proceedings: Eight Symposium on Space Nuclear Power Systems, M. S. El-Genk and M. D. Hoover, eds., Institute for Space Nuclear Power Studies Albuquerque, NM.

Dagle, J.E. and E.P. Coomes (1989) "A Bcam-Powered Electric Orbital Transfer Vehicle: The Advantages of Nuclear Electric Propulsion Without the Concerns Over Nuclear Power," AIAA89-2372, American Institute of Aeronautics and Astronautics, New York.

Wilson, Andrew (1990) Space Directory 1990-91, Jane's Information Group, Alexandria, VA. 

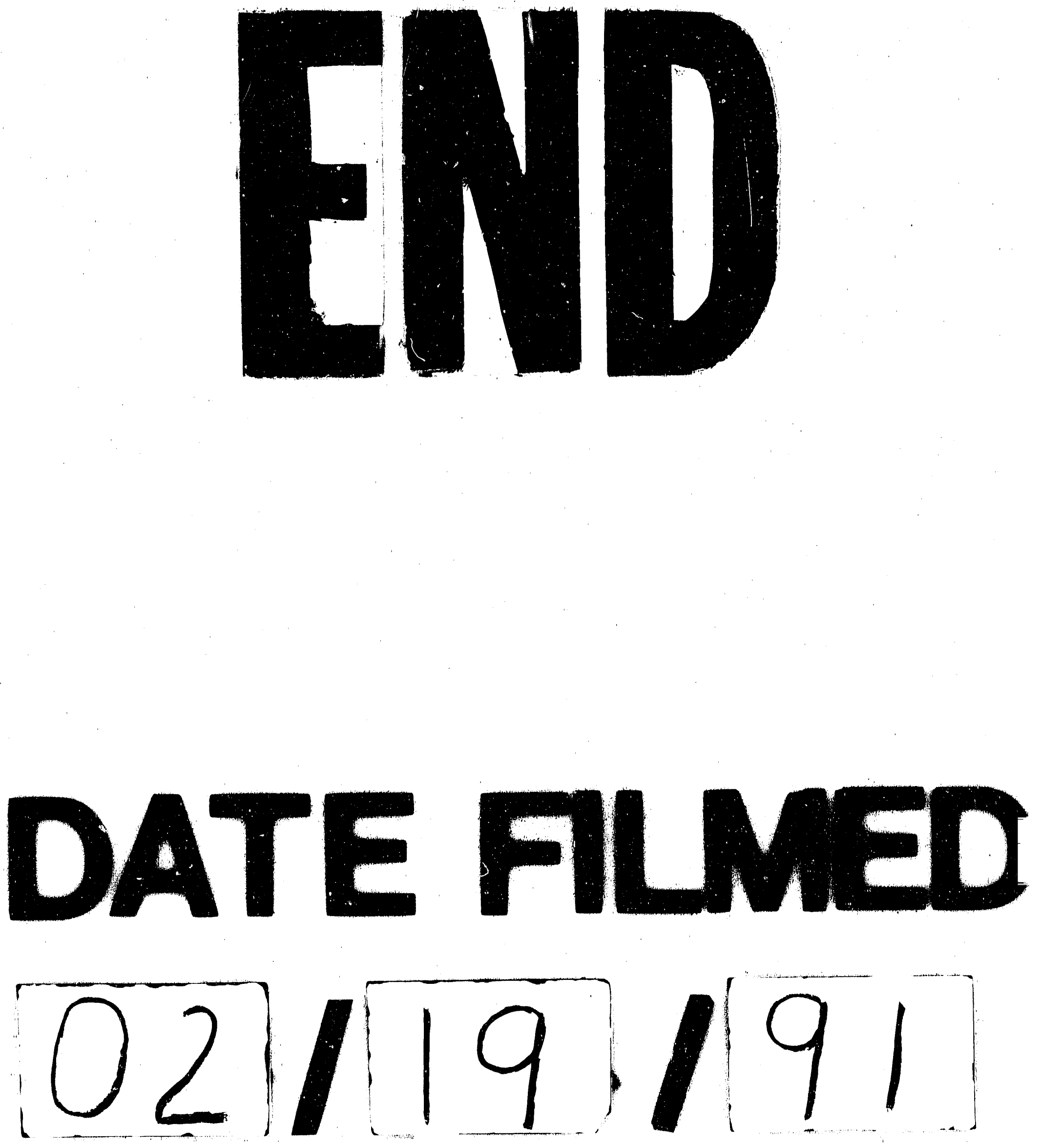


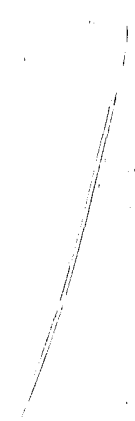

